\title{
Continuing Medical Education for Primary Care Physicians in Israel: A Cross-Sectional Study
}

\author{
Pesach Shvartzman, ${ }^{1}$ Howard Tandeter, ${ }^{1}$ Daniel Vardy, ${ }^{2,3}$ Eran Matz, \\ Anthony Heymann, ${ }^{4,5}$ and Roni Peleg ${ }^{1}$ \\ ${ }^{1}$ Department of Family Medicine and Siaal Research Center for Family Medicine and Primary Care, Faculty of Health Sciences, \\ Ben-Gurion University of the Negev, Clalit Health Services, P.O. Box 653, 84105 Beer-Sheva, Israel \\ ${ }^{2}$ Faculty of Health Sciences, Ben-Gurion University of the Negev, P.O. Box 653, 84105 Beer-Sheva, Israel \\ ${ }^{3}$ Leumit Health Services, $64738 \mathrm{Tel}$ Aviv, Israel \\ ${ }^{4}$ Department of Family Medicine, Tel Aviv University, 69978 Tel Aviv, Israel \\ ${ }^{5}$ Department of Community Medicine, Maccabi Healthcare Services, 68125 Tel Aviv, Israel
}

Correspondence should be addressed to Roni Peleg; pelegr@bgu.ac.il

Received 12 November 2012; Revised 8 May 2013; Accepted 21 May 2013

Academic Editor: Angela Gentili

Copyright ( 2013 Pesach Shvartzman et al. This is an open access article distributed under the Creative Commons Attribution License, which permits unrestricted use, distribution, and reproduction in any medium, provided the original work is properly cited.

\begin{abstract}
Acquiring a medical degree is only the beginning of a prolonged learning process. At some point, formal studies end, and continuing medical education (CME) may be left to personal initiative. To assess lifetime learning (LL) and CME among primary care physicians in Israel, a self-administered questionnaire, based on the Jefferson Scale of Physician Lifelong Learning (JSPLL), was mailed to 4,104 primary care physicians. A total of 979 completed the study, $53.4 \%$ males with a mean age of $51.8 \pm 8.3$ (range 31-79). A logistic regression model showed that male gender ( $\mathrm{OR}=1.5, P<0.05)$, teaching $(\mathrm{OR}=4.5, P<0.0001)$, and not working in a rural clinic $(\mathrm{OR}=0.6, P<0.01)$, increased the LL score. The results of the study demonstrate a need to address special subgroups that have a lower tendency to engage in LL activities. Policymakers should develop strategies to increase these physicians' interest in LL activities and the accessibility of these activities to them, including the availability of LL resources at home so physicians can get updates at their convenience. Primary care physicians should also be encouraged to become involved in teaching of any type, as this is a facilitating factor for LL activities.
\end{abstract}

\section{Introduction}

Acquiring a medical degree is only the beginning of a prolonged learning process. Medical schools provide the basic infrastructure of knowledge and skills. Formal studies continue during residency training and sometimes in subspecialty or fellowship programs that provide trainees with the necessary skills to perform more specific tasks. But at a certain point in time, "formal" structured studies end, and, in countries in which the recertification of physicians' skills and knowledge is not required, continuing education is left to personal initiative.

Hospitals have a long tradition of continuing medical education (CME) and professional updating that are integrated into the regular work schedule. This includes staff meetings, radiology meetings, clinical-pathological meetings, and journal clubs. Community physicians usually work in solo or small group practices with a limited number of other physicians, and CME is not an integral part of their work schedule. The tradition of teaching and research in family medicine is a recent development, so it is much less established than in the hospital setting. As the focus of patient care moves to the community, the focus of CME should follow.

The ways in which physicians continue to update themselves at the end of their formal studies have been described using different terms, including self-directed learning, self-educative approach, self-initiative learning, active learning, independent learning, contextual learning, CME, 
TABLE 1: Study population demography and physician practice characteristics $(n=979)$

\begin{tabular}{|c|c|c|}
\hline & $n$ & $\%$ \\
\hline \multicolumn{3}{|c|}{ Demographic characteristics } \\
\hline \multicolumn{3}{|l|}{ Age } \\
\hline $30-50$ & 380 & $41.1 \%$ \\
\hline $51+$ & 545 & $58.9 \%$ \\
\hline Average \pm st. dv. & \multicolumn{2}{|c|}{$51.8 \pm 8.3$} \\
\hline \multirow{2}{*}{ Range } & \multicolumn{2}{|c|}{$31-79$} \\
\hline & 925 & $(\mathrm{mis}=54)$ \\
\hline \multicolumn{3}{|l|}{ Gender } \\
\hline \multirow[t]{2}{*}{ Male } & 509 & $53.4 \%$ \\
\hline & 954 & $(\mathrm{mis}=25)$ \\
\hline \multicolumn{3}{|l|}{ Country of birth } \\
\hline Israel & 378 & $40.3 \%$ \\
\hline East Europe and USSR & 323 & $34.4 \%$ \\
\hline \multirow[t]{2}{*}{ Other } & 238 & $25.3 \%$ \\
\hline & 939 & $(\mathrm{mis}=40)$ \\
\hline
\end{tabular}

\begin{tabular}{lcc}
\hline \multicolumn{3}{c}{ Physician and practice characteristics } \\
\hline Graduated Medical School in \\
Israel & 344 & $36.5 \%$ \\
Other & 598 & $63.5 \%$ \\
& 942 & $(\mathrm{mis}=37)$
\end{tabular}

Years as a physician
1-10
11-19
$20+$
Average \pm st. dv.
Range

Specialists in (more than one answer could be marked)

$\begin{array}{lcc}\text { Family physician } & 451 & 43.2 \% \\ \text { Pediatrician } & 215 & 20.6 \% \\ \text { Internal medicine } & 138 & 13.2 \% \\ \text { General practitioner } & 151 & 14.5 \% \\ \text { Geriatrician } & 22 & 2.1 \% \\ \text { Other } & 67 & 6.4 \% \\ & 1044 & \end{array}$

Graduated specialty in

Israel

East Europe and USSR

Other

$\begin{array}{cc}47 & 5.3 \% \\ 178 & 20.0 \% \\ 665 & 74.7 \% \\ & 25.5 \pm 8.7 \\ & 4-54 \\ 890 & (\text { mis }=89)\end{array}$

Years as a specialist

\begin{tabular}{lll}
$1-10$ & 303 & $39.9 \%$ \\
$11-19$ & 218 & $28.7 \%$ \\
$20+$ & 239 & $31.4 \%$ \\
\hline
\end{tabular}

TABLE 1: Continued.

\begin{tabular}{lcc}
\hline & $n$ & $\%$ \\
\hline Average \pm st. dv. & & $14.8 \pm 9.3$ \\
Range & & $0-51$ \\
& 760 & $($ mis $=67)$
\end{tabular}

Number of years in practice in primary care in Israel

$\begin{array}{lll}1-10 & 226 & 24.5 \% \\ 11-19 & 397 & 43.1 \% \\ 20+ & 298 & 32.4 \%\end{array}$

Average \pm st. dv.

Range

$17.4 \pm 8.7$

$1-50$

$921 \quad(\operatorname{mis}=58)$

Teaching involvement

Yes

$333 \quad 36.5 \%$

$913 \quad(\mathrm{mis}=66)$

Academic affiliation

Yes

244

$27.7 \%$

$244 \quad($ mis $=97)$

Were you a partner in

planning/developing

teaching programs?

Yes

$234 \quad 26.0 \%$

$900 \quad(\mathrm{mis}=79)$

Characteristic of main working clinic

Urban
Rural
Child health center
Other

$640 \quad 66.7 \%$

$119 \quad 12.4 \%$

$55 \quad 5.7 \%$

$45 \quad 4.7 \%$

$959 \quad(\mathrm{mis}=20)$

Position

Head of clinic

$166 \quad 17.4 \%$

Primary physician

$713 \quad 74.7 \%$

$75 \quad 7.9 \%$

$954 \quad($ mis $=25)$

Number of population under your care (main clinic)
$\leq 1000$
1001-1500
$1500+$
Average \pm st. dv.
Range

$238 \quad 30.3 \%$

$292 \quad 37.2 \%$

$32.5 \%$

$1520.5 \pm 1102.7$

50-9500

$785 \quad(\mathrm{mis}=194)$

Other clinics you work at (more than one answer could be marked)
Urban
Rural
Child health center
Other

$62.3 \%$

$16.1 \%$

$1.7 \%$

$19.9 \%$ 
TABLE 1: Continued.

\begin{tabular}{lcc}
\hline & $n$ & $\%$ \\
\hline $\begin{array}{l}\text { Number of hours seeing patients/week } \\
\leq 30\end{array}$ & 255 & $27.9 \%$ \\
$31-45$ & 574 & $62.7 \%$ \\
$45+$ & 86 & $9.4 \%$ \\
Average \pm st. dv. & \multicolumn{2}{c}{$34.1 \pm 10.5$} \\
$\quad$ Range & \multicolumn{2}{c}{$2-90$} \\
& 915 & $(\mathrm{mis}=64)$ \\
Average number of patients seen/day & \multicolumn{2}{|}{} \\
(7 hours) & 114 & $12.7 \%$ \\
$\quad \leq 20$ & 309 & $34.3 \%$ \\
$21-35$ & 356 & $39.5 \%$ \\
$36-50$ & 122 & $13.5 \%$ \\
$51+$ & \multicolumn{2}{c}{$38.8 \pm 14.9$} \\
Average \pm st. dv. & \multicolumn{2}{c}{$4-110$} \\
Range & 901 & $(\mathrm{mis}=78)$ \\
\hline
\end{tabular}

and distance learning. Lately, all these have been included in one terminological basket under the rubric of lifelong learning (LL) [1].

Over the years, different tools have been developed to evaluate LL. In 1977, Guglielmino developed a Self-Directed Learning Readiness Scale (SDLRS) [2] that contained 58 Likert-like items such as "I love to learn." A short version of the SDLRS, which includes only 28 items from the original scale, was prepared by Bligh in 1993 [3]. Another scale to identify predictors of self-directed learning was developed by Oddi [4] in 1986, but subsequent studies did not provide consistent support for its validity $[5,6]$.

In 2003, Hojat et al. [1, 7] developed a tool to measure LL for physicians that had supporting psychometric evidence. A 37-item questionnaire was developed based on a review of the literature and the results of two pilot studies. Psychometric analyses of the responses of 160 physicians identified 19 items that were included in the final version of the Jefferson Scale of Physician Lifelong Learning (JSPLL).

Using this tool, we evaluated the characteristics of primary care physicians who have adopted LL as a professional principle. This information is especially important in countries like Israel where there is no legal requirement for CME or recertification, and self-initiative for LL remains the basis for assuring professional quality after formal medical studies end.

\section{Methods}

2.1. Setting. In Israel, a National Insurance Law was passed in 1995, which mandates the provision of health services through four Health Maintenance Organizations (HMOs). In 1970, Clalit Health Services (CHS), the largest HMO in Israel, provided primary care physicians working in community clinics with a paid work day for ongoing educational update needs. The continuing education program is provided by the universities through CME schools [8]. Each physician working for the CHS has a clause in their contract that guarantees one paid CME day a week. The other HMOs offer a paid half-day or none at all, depending on the physician's contract. The Ministry of Health has not provided specific resources for long-term CME for physicians.

2.2. Study Population. The study included primary care physicians who have worked in the community setting for over two years and who work in a primary care setting for at least 15 hours per week. Primary care physicians are defined as general practitioners, pediatricians, family medicine specialists, internal medicine specialists, and geriatricians working in CHS community clinics (2,417 physicians), Maccabi Health Services (1,245 physicians), and Leumit Health Services (442 physicians).

2.3. Study Tool. A structured self-administered questionnaire was constructed for the participating physicians. It included the following.

(1) The JSPLL, which assesses physicians' attitudes toward LL. The questionnaire was translated from English to Hebrew using the back-translation method [9] and was consequently culturally adapted. No validation tests were performed. It includes 19 items regarding basic elements of CME graded on a 4-point Likert scale (strongly disagree $=1$, disagree $=2$, agree $=3$, and strongly agree $=4$ ) [1]. The higher the score on the JSPLL, the greater the orientation toward lifelong learning. Factor analysis of the JSPLL depicts four sub-scales that are consistent with known characteristics of continuing education: (1) beliefs and motivation for professional learning, (2) educational activities, (3) recognition of educational opportunities, and (4) technical skills in searching for information [10]. The coefficient $\alpha$ for this tool was 0.89 , and the test-retest value was 0.91 [11]. The authors concluded that the four sub-scales of the JSPLL are relevant to the various aspects of CME, as described by others [10-14].

(2) Physicians' characteristics: age, gender, number of years in primary care, medical school, and specialty.

(3) Clinic characteristics: urban/rural, number of patients, solo practice/group practice, and number of visits/day.

(4) CME activities: specific questions regarding frequency of activities, number of papers read/week, participation in specific lectures during the past year, and other activities.

2.4. Data Collection. Study questionnaires were mailed to physicians with a stamped addressed envelope for a return mail. A second mailing to physicians who did not complete the questionnaire was sent out after one month. In all, study questionnaires were mailed up to three times. 
TABLE 2: Jefferson Scale of Physician Lifelong Learning (JSPLL) $(n=979)$.

\begin{tabular}{|c|c|c|c|c|}
\hline Please note the degree you agree with the following statements (1-strongly disagree; 4-strongly agree) & Mean & Std. & Median & $n$ \\
\hline Lifelong learning is a professional responsibility of all physicians & 3.7 & 0.5 & 4 & 951 \\
\hline $\begin{array}{l}\text { Rapid changes in medical science require constant updating of knowledge and development of new } \\
\text { professional skills }\end{array}$ & 3.7 & 0.5 & 4 & 959 \\
\hline I enjoy reading articles in which issues of my professional interest are discussed & 3.6 & 0.5 & 4 & 956 \\
\hline I believe that I would fall behind if I stopped learning about new developments in my specialty & 3.6 & 0.6 & 4 & 953 \\
\hline One of the important goals of medical school is to develop students' lifelong learning skills & 3.6 & 0.6 & 4 & 956 \\
\hline I recognize my need to constantly acquire new professional knowledge & 3.5 & 0.6 & 4 & 957 \\
\hline Searching for the answer to a question is, in and by itself, rewarding & 3.3 & 0.7 & 3 & 905 \\
\hline I attend educational programs whether or not CME credit is offered & 3.2 & 0.9 & 3 & 954 \\
\hline I take every opportunity to gain new knowledge/skills that are important to my profession & 3.2 & 0.7 & 3 & 956 \\
\hline My preferred approach in finding an answer to a question is to search the appropriate computer databases & 3.2 & 0.8 & 3 & 953 \\
\hline
\end{tabular}

All participants gave their informed consent prior to participation in the study.

2.5. Data Analysis. Questionnaires were coded and entered in the study database using the Epidata 2.1 software. Data analysis was conducted with the SPSS 14.0 statistical software. Comparative one-way analysis was performed between different levels of LL (high versus low) using chi-square for categorical variables and ANOVA for continuous variables with $P<0.05$ set as statistically significant for all analyses. A logistic regression model was constructed to predict physicians with high LL scores, controlling for clinic and patient variables.

\section{Results}

3.1. Study Population. The questionnaires were mailed to 4,104 primary care physicians working at one of the three HMOs participating in the study, of whom 979 completed the questionnaire (23.9\% response rate). No statistically significant differences were found between responders and nonresponders in terms of gender or years of employment at CHS. The majority of the study population was male (53.4\%), with a mean age of $51.8 \pm 8.3$ (range $31-79$ ), and $40.3 \%$ was born in Israel. Table 1 depicts the sociodemographic characteristics of the participating physicians.

Among the responders, there were more males $(52.5 \%$ versus $47.0 \%, P=0.013)$, and the group was younger $(49.5 \pm$ 8.1 versus $50.5 \pm 8.1, P=0.017)$. No differences were found in years of experience as a physician.

Physicians were asked to rate their reading and LL practices on a scale from $1-5$.

The three most read sources were English journals (3.6 \pm $1.0)$, free websites $(3.4 \pm 1.2)$, and Hebrew journals (3.3 \pm 1.0$)$. The three most frequent modalities for updating activities in the past year were scientific conferences $(3.5 \pm 1.2)$, clinical meetings in the clinic $(3.4 \pm 1.5)$, and meetings sponsored by pharmaceutical companies $(3.3 \pm 1.2)$.

Participants were asked to note the availability of updating resources they have access to at home, at the work place, and in the medical library. The highest availability was defined as the resource being available both at home and at work. The leading resource noted was a computer with internet access (89.9\%), followed by access to full-text publications (57.6\%).

Participants were asked to rate their attitudes regarding who should be responsible for LL. There was a strong consensus that CME activities should be funded by the HMOs and/or hospitals (4.6 \pm 0.8$)$, that they should take place during regular working hours $(4.0 \pm 1.3)$, and that participants might have to pay for these activities $(4.8 \pm 0.7)$. There was a low degree of agreement that attending LL activities/CME courses should be a condition for recertification $(2.8 \pm 1.4)$ and that physicians should be trusted to study on their own without a need for CME courses $(2.8 \pm 1.2)$.

3.2. The Jefferson Scale of Physician Lifelong Learning (JSPLL). Table 2 depicts the results of the JSPLL questionnaire regarding the LL habits of the participating physicians. Of the 979 physicians who responded, 828 completed the full questionnaire. The mean score was $57.7 \pm 7.5$ (of a maximum of 76). Based on these results, three groups were identified: (1) the bottom third with a low LL activity level (score 33-54), (2) a middle activity level (54-61), and (3) an upper third with a high LL activity level (62-76).

Physicians with high and low LL scores were compared. A comparison of demographic characteristics appears in Table 3. The high LL group included significantly more males (50.8\% versus $49.2 \%, P=0.03$ ), Israeli-born physicians (54.5\% versus $45.5 \%, P<0.01$ ), graduates from Israeli medical schools (54.0\% versus $46.0 \%, P<0.01$ ), physicians involved in teaching (70.3\% versus $29.7 \%, P<0.0001)$, physicians with an academic affiliation (71.4\% versus $28.6 \%$, $P<0.0001)$, physicians who participated in the development of educational programs $(74.0 \%$ versus $26.0 \%, P<0.001)$, and physicians who held a position as a clinic director $(65.3 \%$ versus $34.7 \%, P<0.001)$.

Physicians with higher scores were significantly more likely to have rated each of the different reading sources, 
TABLE 3: Comparison of demographic and practice characteristics between physicians with high* and low ${ }^{* *}$ JSPLL scores $(N=255$ versus $N=288)$.

\begin{tabular}{|c|c|c|c|c|c|c|}
\hline & \multicolumn{2}{|c|}{$\begin{array}{l}\text { JSPLL lower third scores } \\
\qquad(N=288)\end{array}$} & \multicolumn{2}{|c|}{$\begin{array}{l}\text { JSPLL upper third scores } \\
\qquad(N=255)\end{array}$} & \multirow[t]{2}{*}{ Total } & \multirow[t]{2}{*}{$P$ value } \\
\hline & $N$ & $\%$ & $N$ & $\%$ & & \\
\hline \multicolumn{7}{|l|}{ Age } \\
\hline $30-50$ & 112 & $53.8 \%$ & 96 & $46.2 \%$ & 208 & \\
\hline $51+$ & 153 & $50.7 \%$ & 149 & $49.3 \%$ & 302 & \\
\hline Average \pm st. dv & \multicolumn{2}{|c|}{$51.87 \pm 8.74$} & \multicolumn{2}{|c|}{$51.86 \pm 7.65$} & & 0.993 \\
\hline \multirow[t]{2}{*}{ Range } & \multicolumn{2}{|c|}{$32-79$} & \multicolumn{2}{|c|}{$32-68$} & & \\
\hline & 265 & $(\mathrm{mis}=23)$ & 245 & $(\mathrm{mis}=10)$ & 510 & \\
\hline \multicolumn{7}{|l|}{ Gender } \\
\hline \multirow[t]{2}{*}{ Male } & 150 & $49.2 \%$ & 155 & $50.8 \%$ & 305 & \multirow{2}{*}{0.031} \\
\hline & 282 & $(\mathrm{mis}=6)$ & 248 & $(\operatorname{mis}=7)$ & 530 & \\
\hline \multicolumn{7}{|l|}{ Country of Birth } \\
\hline Israel & 110 & $45.5 \%$ & 132 & $54.5 \%$ & 242 & \multirow{4}{*}{0.007} \\
\hline East Europe and USSR & 89 & $61.4 \%$ & 56 & $38.6 \%$ & 145 & \\
\hline \multirow[t]{2}{*}{ Other } & 74 & $55.6 \%$ & 59 & $44.4 \%$ & 133 & \\
\hline & 273 & $(\mathrm{mis}=15)$ & 247 & $(\operatorname{mis}=8)$ & 520 & \\
\hline \multicolumn{7}{|l|}{ Years in Israel } \\
\hline$\leq 10$ & 7 & $70.0 \%$ & 3 & $30.0 \%$ & 10 & \multirow{5}{*}{0.313} \\
\hline $10+$ & 142 & $56.8 \%$ & 108 & $43.2 \%$ & 250 & \\
\hline Average \pm st. dv. & \multicolumn{2}{|c|}{$27.11 \pm 13.82$} & \multicolumn{2}{|c|}{$27.91 \pm 13.02$} & & \\
\hline \multirow[t]{2}{*}{ Range } & \multicolumn{2}{|c|}{ 6-70 } & \multicolumn{2}{|c|}{ 8-91 } & & \\
\hline & 149 & $(\mathrm{mis}=14)$ & 111 & $(\operatorname{mis}=4)$ & 260 & \\
\hline Graduated Medical School & & & & & & \\
\hline Israel & 108 & $46.0 \%$ & 127 & $54.0 \%$ & 235 & \\
\hline Other & 170 & $59.0 \%$ & 118 & $41.0 \%$ & 288 & 0.009 \\
\hline & 278 & $(\mathrm{mis}=10)$ & 245 & $(\mathrm{mis}=10)$ & 523 & \\
\hline Years as a physician & & & & & & \\
\hline $1-10$ & 14 & $51.9 \%$ & 13 & $48.1 \%$ & 27 & \\
\hline $11-19$ & 48 & $49.5 \%$ & 49 & $50.5 \%$ & 97 & \\
\hline $20+$ & 196 & $53.1 \%$ & 173 & $46.9 \%$ & 369 & 0.815 \\
\hline Average \pm st. dv & & & & & & \\
\hline Range & & & & & & \\
\hline & 258 & $(\mathrm{mis}=30)$ & 235 & $(\mathrm{mis}=20)$ & 493 & \\
\hline $\begin{array}{l}\text { Specialists in (more than o } \\
\text { could be marked) }\end{array}$ & & & & & & \\
\hline Family physician & 132 & $50.8 \%$ & 128 & $49.2 \%$ & 260 & 0.176 \\
\hline Pediatrician & 61 & $50.4 \%$ & 60 & $49.6 \%$ & 121 & 0.29 \\
\hline Internal medicine & 41 & $51.3 \%$ & 39 & $48.8 \%$ & 80 & 0.41 \\
\hline General practitioner & 43 & $65.2 \%$ & 23 & $34.8 \%$ & 66 & 0.024 \\
\hline Geriatrician & 4 & $36.4 \%$ & 7 & $63.6 \%$ & 11 & 0.345 \\
\hline Other & 12 & $29.3 \%$ & 29 & $70.7 \%$ & 41 & 0.001 \\
\hline & 293 & & 286 & & 579 & \\
\hline Graduated specialty in & & & & & & \\
\hline Israel & 204 & $48.8 \%$ & 214 & $51.2 \%$ & 418 & \\
\hline Abroad & 29 & $61.7 \%$ & 18 & $38.3 \%$ & 47 & 0.09 \\
\hline & 233 & $(\mathrm{mis}=12)$ & 232 & & 465 & \\
\hline
\end{tabular}


TABle 3: Continued.

\begin{tabular}{|c|c|c|c|c|c|c|}
\hline & \multicolumn{2}{|c|}{$\begin{array}{l}\text { JSPLL lower third scores } \\
\qquad(N=288)\end{array}$} & \multicolumn{2}{|c|}{$\begin{array}{l}\text { JSPLL upper third scores } \\
\qquad(N=255)\end{array}$} & \multirow[t]{2}{*}{ Total } & \multirow[t]{2}{*}{$P$ value } \\
\hline & $N$ & $\%$ & $N$ & $\%$ & & \\
\hline \multicolumn{7}{|l|}{ Years as a specialist } \\
\hline $1-10$ & 86 & $52.8 \%$ & 77 & $47.2 \%$ & 163 & \multirow{6}{*}{0.629} \\
\hline $11-19$ & 66 & $47.8 \%$ & 72 & $52.2 \%$ & 138 & \\
\hline $20+$ & 68 & $48.2 \%$ & 73 & $51.8 \%$ & 141 & \\
\hline Average \pm st. dv & \multicolumn{2}{|c|}{$14.72 \pm 9.35$} & \multicolumn{2}{|c|}{$15.21 \pm 8.48$} & & \\
\hline \multirow[t]{2}{*}{ Range } & \multicolumn{2}{|c|}{$1-51$} & \multicolumn{2}{|c|}{$1-37$} & & \\
\hline & 220 & $(\mathrm{mis}=25)$ & 222 & $(\mathrm{mis}=10)$ & 442 & \\
\hline \multicolumn{7}{|c|}{$\begin{array}{l}\text { Number of years in practice in primary } \\
\text { care in Israel }\end{array}$} \\
\hline $1-10$ & 64 & $54.2 \%$ & 54 & $45.8 \%$ & 118 & \multirow{3}{*}{0.426} \\
\hline $11-19$ & 121 & $57.1 \%$ & 91 & $42.9 \%$ & 212 & \\
\hline $20+$ & 94 & $50.5 \%$ & 92 & $49.5 \%$ & 186 & \\
\hline Average \pm st. dv & \multicolumn{2}{|c|}{$17.44 \pm 8.74$} & \multicolumn{2}{|c|}{$18.19 \pm 8.63$} & & \\
\hline \multirow[t]{2}{*}{ Range } & \multicolumn{2}{|c|}{$1-50$} & \multicolumn{2}{|c|}{$2-40$} & & \\
\hline & 279 & $(\operatorname{mis}=9)$ & 237 & $(\mathrm{mis}=18)$ & 516 & \\
\hline \multicolumn{7}{|l|}{ Teaching involvement } \\
\hline \multirow[t]{2}{*}{ Yes } & 65 & $29.7 \%$ & 154 & $70.3 \%$ & 219 & \multirow{2}{*}{$<0.0001$} \\
\hline & 277 & $(\mathrm{mis}=11)$ & 242 & $(\mathrm{mis}=13)$ & 519 & \\
\hline \multicolumn{7}{|l|}{ Academic affiliation } \\
\hline \multirow[t]{2}{*}{ Yes } & 46 & $28.6 \%$ & 115 & $71.4 \%$ & 161 & \multirow{2}{*}{$<0.0001$} \\
\hline & 272 & $(\operatorname{mis}=16)$ & 233 & $(\mathrm{mis}=22)$ & 505 & \\
\hline $\begin{array}{l}\text { Were you a partner in } \\
\text { planning/developing } \\
\text { teaching programs? }\end{array}$ & & & & & & \\
\hline Yes & 40 & $26.0 \%$ & 114 & $74.0 \%$ & 154 & $<0.0001$ \\
\hline & 270 & $(\mathrm{mis}=18)$ & 237 & $(\mathrm{mis}=18)$ & 507 & -0.0001 \\
\hline Position & & & & & & \\
\hline Head of clinic & 35 & $34.7 \%$ & 66 & $65.3 \%$ & 101 & \\
\hline Primary physician & 231 & $59.7 \%$ & 156 & $40.3 \%$ & 387 & \\
\hline Other & 14 & $33.3 \%$ & 28 & $66.7 \%$ & 42 & $<0.0001$ \\
\hline & 280 & $(\operatorname{mis}=8)$ & 250 & $(\mathrm{mis}=5)$ & 530 & \\
\hline Characteristic of main & & & & & & \\
\hline Urban & 232 & $57.9 \%$ & 169 & $42.1 \%$ & 401 & \\
\hline Rural/kibbutz & 34 & $45.3 \%$ & 41 & $54.7 \%$ & 75 & \\
\hline Child health center & 9 & $27.3 \%$ & 24 & $72.7 \%$ & 33 & $<0.0001$ \\
\hline Other & 10 & $35.7 \%$ & 18 & $64.3 \%$ & 28 & \\
\hline & 285 & $(\operatorname{mis}=3)$ & 252 & $(\mathrm{mis}=3)$ & 537 & \\
\hline Position & & & & & & \\
\hline Head of clinic & 35 & $34.7 \%$ & 66 & $65.3 \%$ & 101 & \\
\hline Primary physician & 231 & $59.7 \%$ & 156 & $40.3 \%$ & 387 & $<0.0001$ \\
\hline Other & 14 & $33.3 \%$ & 28 & $66.7 \%$ & 42 & -0.0001 \\
\hline & 280 & $(\operatorname{mis}=8)$ & 250 & $(\mathrm{mis}=5)$ & 530 & \\
\hline $\begin{array}{l}\text { Number of population } \\
\text { (main clinic) }\end{array}$ & & & & & & \\
\hline$\leq 1000$ & 69 & $54.8 \%$ & 57 & $45.2 \%$ & 126 & \\
\hline $1001-1500$ & 92 & $57.9 \%$ & 67 & $42.1 \%$ & 159 & \\
\hline
\end{tabular}


TABLe 3: Continued.

\begin{tabular}{|c|c|c|c|c|c|c|}
\hline & \multicolumn{2}{|c|}{$\begin{array}{l}\text { JSPLL lower third scores } \\
\qquad(N=288)\end{array}$} & \multicolumn{2}{|c|}{$\begin{array}{l}\text { JSPLL upper third scores } \\
\qquad(N=255)\end{array}$} & \multirow[t]{2}{*}{ Total } & \multirow[t]{2}{*}{$P$ value } \\
\hline & $N$ & $\%$ & $N$ & $\%$ & & \\
\hline $1500+$ & 73 & $46.5 \%$ & 84 & $53.5 \%$ & 157 & 0.115 \\
\hline Average \pm st. dv. & \multicolumn{2}{|c|}{$1433.35 \pm 880.15$} & \multicolumn{2}{|c|}{$1603.85 \pm 1203.89$} & & \\
\hline \multirow[t]{2}{*}{ Range } & \multicolumn{2}{|c|}{$80-8000$} & \multicolumn{2}{|c|}{ 60-9999 } & & \\
\hline & 234 & $(\mathrm{mis}=54)$ & 208 & $(\mathrm{mis}=47)$ & 442 & \\
\hline \multicolumn{7}{|c|}{$\begin{array}{l}\text { Other clinics you work at (more than one } \\
\text { answer could be marked) }\end{array}$} \\
\hline Urban & 85 & $49.1 \%$ & 88 & $50.9 \%$ & 173 & 0.212 \\
\hline Rural/kibbutz & 17 & $48.6 \%$ & 18 & $51.4 \%$ & 35 & 0.584 \\
\hline Child health center & 0 & $0.0 \%$ & 4 & $100.0 \%$ & 4 & 0.048 \\
\hline \multirow[t]{2}{*}{ Other } & 20 & $34.5 \%$ & 38 & $65.5 \%$ & 58 & 0.003 \\
\hline & 288 & & 255 & & 543 & \\
\hline \multicolumn{7}{|c|}{ Number of hours seeing patients/week } \\
\hline$\leq 30$ & 78 & $49.4 \%$ & 80 & $50.6 \%$ & 158 & \\
\hline $31-45$ & 167 & $54.6 \%$ & 139 & $45.4 \%$ & 306 & 0.566 \\
\hline $45+$ & 25 & $53.2 \%$ & 22 & $46.8 \%$ & 47 & \\
\hline Average \pm st. dv & \multicolumn{2}{|c|}{$33.86 \pm 10.64$} & \multicolumn{2}{|c|}{$32.92 \pm 11.03$} & & \\
\hline \multirow[t]{2}{*}{ Range } & \multicolumn{2}{|c|}{$5-65$} & \multicolumn{2}{|c|}{$2-60$} & & \\
\hline & 270 & $(\mathrm{mis}=18)$ & 241 & $(\mathrm{mis}=14)$ & 511 & \\
\hline \multicolumn{7}{|c|}{$\begin{array}{l}\text { Average number of patients seen/day } \\
\text { ( } 7 \text { hours) }\end{array}$} \\
\hline$\leq 20$ & 36 & $52.9 \%$ & 32 & $47.1 \%$ & 68 & \\
\hline $21-35$ & 89 & $50.9 \%$ & 86 & $49.1 \%$ & 175 & \\
\hline $36-50$ & 103 & $53.4 \%$ & 90 & $46.6 \%$ & 193 & 0.467 \\
\hline $51+$ & 44 & $62.0 \%$ & 27 & $38.0 \%$ & 71 & \\
\hline Average \pm st. dv & \multicolumn{2}{|c|}{$39.86 \pm 15.90$} & \multicolumn{2}{|c|}{$37.41 \pm 15.16$} & & \\
\hline \multirow[t]{2}{*}{ Range } & \multicolumn{2}{|c|}{$6-100$} & \multicolumn{2}{|c|}{$5-100$} & & \\
\hline & 272 & $(\mathrm{mis}=16)$ & 235 & $(\mathrm{mis}=20)$ & 507 & \\
\hline
\end{tabular}

${ }^{*}$ High JSPLL score-upper third score (high LL activities score: 62-76).

${ }^{* *}$ Low JSPLL score-bottom third score (low LL activities score: 33-54).

participated in more update meetings, and utilized each of the data sources to a greater degree (Table 4 ).

If the updating resource was accessible both at work and at home, it was rated as highly available. For each of the updating resources, higher availability was noted for physicians in the upper third LL group. In addition, the physicians in the upper third LL group strongly agreed that CME activities should be funded by the HMOs and/or hospitals (4.68 versus 4.48, $P<0.01$ ) and that CME should be a condition for recertification (3.1 versus $2.5, P<0.0001$ ).

A logistic regression model was constructed to predict physician characteristics that correlate with higher LL scores. The independent variable was having an upper third score in the JSPLL questionnaire. The dependent variables included in the model were: male gender $(\mathrm{OR}=1.501,95 \%$ CI 1.044-2.159), involvement in teaching ( $\mathrm{OR}=4.460,95 \%$ CI 3.084-6.448), and a rural clinic as the main work setting $(\mathrm{OR}=0.601,95 \% \mathrm{CI} 0421-0.856)$. The number of years working in primary care in Israel, the number of patients seen, the number of hours spent seeing patients a week, and specialty status were not included in the final model. The variable, years in practice, was also not included as it had a high degree of correlation with physician age (Table 5).

\section{Discussion}

Hospitals have a long tradition of CME activities that are an integral part of the regular working schedule, while primary care physicians work in solo or group practices, and CME activities are usually not included in their regular working hours. Thus, it is important to understand which CME activities are available in the primary care setting.

Since the response rate in our study was only $23.9 \%$, it might be assumed that the study sample does not represent the study population. The response rate may have been higher among physicians who do participate in CME (and may represent particular age and gender groupings), so that 
TABLE 4: Comparison of the updating habits of the lower and upper third respondents $(N=255$ versus $N=288)$.

\begin{tabular}{|c|c|c|c|c|c|c|c|c|c|}
\hline & \multicolumn{4}{|c|}{ JSPLL bottom third scores $(N=288)$} & \multicolumn{4}{|c|}{ JSPLL upper third scores $(N=255)$} & \multirow{2}{*}{$P$ value } \\
\hline & Mean & Std. & Median & $N$ & Mean & Std. & Median & $N$ & \\
\hline \multicolumn{10}{|c|}{ Reading update (1-not at all; 5-very much) } \\
\hline Professional textbooks & 2.68 & 0.98 & 3 & 277 & 3.48 & 1.03 & 3 & 249 & $<0.0001$ \\
\hline Hebrew journals & 3.09 & 0.93 & 3 & 283 & 3.61 & 1.11 & 4 & 248 & $<0.0001$ \\
\hline Foreign language journals & 3.15 & 1.02 & 3 & 279 & 4.18 & 0.86 & 4 & 249 & $<0.0001$ \\
\hline Pharmaceutical companies publications & 2.63 & 0.97 & 3 & 277 & 2.82 & 1.1 & 3 & 240 & 0.039 \\
\hline $\begin{array}{l}\text { Membership-based internet sites } \\
\text { (exp. MD consult) }\end{array}$ & 2.67 & 1.34 & 3 & 276 & 3.92 & 1.23 & 4 & 249 & $<0.0001$ \\
\hline $\begin{array}{l}\text { Nonmember-based internet sites } \\
\text { (exp. medscape) }\end{array}$ & 3.01 & 1.22 & 3 & 280 & 3.98 & 1.12 & 4 & 250 & $<0.0001$ \\
\hline Self-learning CD & 1.58 & 0.94 & 1 & 269 & 2.05 & 1.26 & 2 & 244 & $<0.0001$ \\
\hline IMA guidelines & 2.87 & 1.19 & 3 & 276 & 3.63 & 1.12 & 4 & 248 & $<0.0001$ \\
\hline \multicolumn{10}{|c|}{ To what degree did you participate in the following updates during the past year (1-not at all; 5-very much) } \\
\hline CME courses (weekly meetings) & 2.93 & 1.78 & 3 & 275 & 3.3 & 1.79 & 4 & 240 & 0.021 \\
\hline CME minicourses & 2.22 & 1.41 & 1 & 257 & 2.89 & 1.62 & 3 & 239 & $<0.0001$ \\
\hline Scientific conferences & 3 & 1.23 & 3 & 275 & 4.18 & 1.04 & 5 & 248 & $<0.0001$ \\
\hline Clinical meetings in the clinic & 2.91 & 1.45 & 3 & 270 & 3.79 & 1.36 & 4 & 234 & $<0.0001$ \\
\hline Clinical meetings in the hospital & 1.92 & 1.27 & 1 & 251 & 2.9 & 1.67 & 3 & 232 & $<0.0001$ \\
\hline Lectures at the hospital/clinic/university & 2.58 & 1.33 & 3 & 264 & 3.72 & 1.35 & 4 & 244 & $<0.0001$ \\
\hline $\begin{array}{l}\text { Pharmaceutical companies sponsored } \\
\text { meetings }\end{array}$ & 3.13 & 1.21 & 3 & 279 & 3.34 & 1.28 & 3 & 250 & 0.052 \\
\hline $\begin{array}{l}\text { Accompanying physician (working } \\
\text { alongside a specialist consultant) }\end{array}$ & 1.89 & 1.33 & 1 & 247 & 2.29 & 1.66 & 1 & 212 & 0.001 \\
\hline \multicolumn{10}{|c|}{$\begin{array}{l}\text { Evaluate the frequency you utilize the following data sources when encountering a diagnostic/treatment problem (1-not at all; 5-very } \\
\text { much) }\end{array}$} \\
\hline Books & 3.23 & 1.16 & 3 & 278 & 3.54 & 1.2 & 4 & 251 & 0.002 \\
\hline Journals & 2.9 & 1.09 & 3 & 275 & 3.9 & 1.09 & 4 & 251 & $<0.0001$ \\
\hline Computerized database & 3.92 & 1.1 & 4 & 277 & 4.74 & 0.61 & 5 & 253 & $<0.0001$ \\
\hline Colleagues at the clinic & 3.23 & 1.23 & 3 & 272 & 3.58 & 1.24 & 4 & 248 & 0.001 \\
\hline Consultation with a specialist & 3.89 & 1.01 & 4 & 279 & 4.1 & 0.97 & 4 & 253 & 0.013 \\
\hline $\begin{array}{l}\text { Sales representative of a pharmaceutical } \\
\text { company }\end{array}$ & 1.96 & 1.05 & 2 & 274 & 1.98 & 1.14 & 2 & 250 & 0.801 \\
\hline $\begin{array}{l}\text { Circulation from the medical } \\
\text { management of the HMO }\end{array}$ & 2.67 & 1.15 & 3 & 276 & 2.94 & 1.19 & 3 & 245 & 0.01 \\
\hline
\end{tabular}

the rate of CME activity may be even lower among those who did not participate. If so, the need for remedial action is even greater. Nevertheless, a study population of 979 physicians, who come from three of the four HMOs in Israel, can provide, at the least, a partial picture of attitudes towards LL among primary care physicians in Israel.

Defining the characteristics of those who have a stronger propensity for LL does not necessarily lead to a course of action that would increase this inclination in others. In many countries, women take most of the responsibility for and burden of raising children and caring for the family [15]. This could lead to a conflict between home and work among female physicians [16] and affect both their interest and opportunity to take part in LL activities. Thus, ways should be sought to encourage female physicians to participate in relevant CME activities and develop LL habits.
A large number of Israeli students study outside of Israel. In many cases, they are likely to have lower LL scores, so this group should also be encouraged, through incentives, to develop LL skills and habits through remedial programs within residency programs.

In a study from Israel, an outcome-based CME program addressed and tried to solve the singular needs of practicing immigrant physicians [17]. This type of program could also lead to increased LL activity.

Factors associated with higher LL scores included involvement in teaching, having an academic affiliation, and/or holding a position as a clinic director. However, these factors are often inherent characteristics that are not fostered by training programs. Still, encouraging physicians to engage in academic activities can lead to positive outcomes. HMOs should encourage physicians' access to university academic 
TABLE 5: Logistic regression results for predicting physicians that will be in the upper third of the JSPLL questionnaire $(N=979)$.

\begin{tabular}{lccc}
\hline Variables included & Odds ratio & CI 95\% & $P$ value \\
\hline $\begin{array}{l}\text { Age (continuous) } \\
\text { Gender }\end{array}$ & 1.019 & $0.996-1.042$ & 0.103 \\
$\quad$ Male & 1.501 & $1.044-2.159$ & 0.028 \\
$\quad$ Female & 1 & & \\
Country of medical school & & & \\
$\quad$ Israel & 1.381 & $0.961-1.986$ & 0.081 \\
$\quad$ Abroad & 1 & & \\
$\begin{array}{l}\text { Involved with teaching } \\
\quad \text { Yes }\end{array}$ & 4.46 & $3.084-6.448$ & $<0.0001$ \\
$\quad$ No & 1 & & \\
Main clinic & & & \\
$\quad$ Other & 0.601 & $0.421-0.856$ & 0.005 \\
$\quad$ Urban & 1 & & \\
\hline
\end{tabular}

departments. It might also be beneficial to identify factors that encourage LL in rural practices and try to adopt them like in urban settings.

The degree of availability of various update modalities is also important. Physicians with high LL scores had greater accessibility to each of the update modalities both at home and at work. It is not surprising that the availability of CME resources and the allocation of time for LL activities during working hours were associated with higher LL activity. Policymakers should find ways to increase accessibility to free LL activities at home and at work in order to enhance LL options.

In a Cochrane review on the effects of CME meetings and workshops on professional practice and health care outcomes [18], the authors concluded that educational meetings alone or combined with other interventions can improve professional practice and the achievement of treatment goals by patients. Studies in medical education have focused primarily on whether continuing education activities are effective in creating a change in the treatment approaches of physicians and improving the health outcomes of patients. A review paper that compared the effect of formal CME teaching (lectures, presentations, and printed materials) with interactive CME programs showed that formal methods had little to no effect, while interactive programs had a medium to high effect [19]. In our study the three most frequent formats for LL were scientific conferences, clinical meetings in the clinic, and meetings sponsored by pharmaceutical companies. Of these, the latter should be the one of greatest concern to us. The current literature on the relationship between the pharmaceutical industry and the medical profession is remarkably consistent [20]. Doctors (and medical students) are influenced by contact with industry, but they incorrectly believe that they are immune to its effects or that they are capable of identifying and averting the danger of any inappropriate bias and influence [21, 22]. Therefore, policy makers should look for ways to allocate funds for CME activities, with the aim of "protecting" physicians from their tendency to depend on pharmaceutical companies for funding.

\section{Conclusions}

Davis et al. [23] suggested that leaders in medical education and related fields should identify high-priority research topics in CME research with the aim of expanding the scope of CME and conducting rigorous scientific studies on the process and effectiveness of CME. Successful research on this topic could provide us with ways to improve all aspects of CME. The results of such research could help policymakers formulate ways to increase physician participation in LL activities and maintain or improve their knowledge, skills, and attitudes even if a long time has passed from the conclusion of their formal medical studies. Further studies should be performed on the contribution of CME to clinical outcomes.

\section{Ethical Approval}

The study received IRB approval from the Meir Medical Center, Kfar Saba, Israel. The work was conducted in accordance with the Declaration of Helsinki (1964).

\section{Conflict of Interests}

The authors declare that they have no conflict of interests.

\section{Funding Statement}

This study was made possible thanks to a grant from The Israel National Institute for Health Policy and Health Services Research. The authors do not have a financial relationship with the organization that sponsored the research.

\section{Acknowledgments}

The authors thank the Israel National Institute for Health Policy and Health Services Research for funding this research. The authors thank Dr. Tamar Freud and the Siaal Research Center for Family Practice and Primary Care for managing data collection and analyzing and interpreting the study data.

\section{References}

[1] M. Hojat, T. J. Nasca, J. B. Erdmann, A. J. Frisby, J. J. Veloski, and J. S. Gonnella, "An operational measure of physician lifelong learning: its development, components and preliminary psychometric data," Medical Teacher, vol. 25, no. 4, pp. 433-437, 2003.

[2] L. M. Guglielmino, Development of the self-directed learning readiness scale [Ph.D. thesis], University of Minnesota, Dissertation Abstracts International, 1977.

[3] J. Bligh, "The S-SDLRS: a short questionnaire about selfdirected learning," Postgraduate Education for General Practice, vol. 4, pp. 121-125, 1993.

[4] F. Oddi, "Development and validation of an instrument to identify self-directed continuing learners," Adult Education Quarterly, vol. 36, pp. 97-107, 1986. 
[5] J. Six, "The generality of the underlying dimensions of the Oddi continuing learning inventory," Adult Education Quarterly, vol. 40, pp. 43-51, 1989.

[6] F. Oddi, "Construct validity of the Oddi continuing learning inventory," Adult Education Quarterly, vol. 40, pp.139-145, 1990.

[7] M. Hojat, J. Veloski, T. J. Nasca, J. B. Erdmann, and J. S. Gonnella, "Assessing physicians' orientation toward lifelong learning," Journal of General Internal Medicine, vol. 21, no. 9, pp. 931-936, 2006.

[8] R. Nevat, "Continuing medical education in primary health care: the Kupat Holim experience," Israel Journal of Medical Sciences, vol. 19, no. 8, pp. 787-790, 1983.

[9] A. D. Sperber, R. F. Develis, and B. Boehlecke, "Cross-cultural translation, methodology and validation," Journal of CrossCultural Psychology, vol. 25, pp. 501-524, 1994.

[10] J. W. Williamson, P. S. German, R. Weiss, E. A. Skinner, and F. Bowes III, "Health science information management and continuing education of physicians. A survey of U.S. primary care practitioners and their opinion leaders," Annals of Internal Medicine, vol. 110, no. 2, pp. 151-160, 1989.

[11] J. W. Ely, R. J. Burch, and D. C. Vinson, “The information needs of family physicians: case-specific clinical questions," Journal of Family Practice, vol. 35, no. 3, pp. 265-269, 1992.

[12] T. Kushnir, A. H. Cohen, and E. Kitai, "Continuing medical education and primary physicians' job stress, burnout and dissatisfaction," Medical Education, vol. 34, no. 6, pp. 430-436, 2000.

[13] R. P. Means, "How family physicians use information sources: implications for new approaches," in Continuing Education for the Health Professions, J. S. Green, S. Grosswald, E. Suter, and D. B. Walthall, Eds., pp. 72-86, Jossey-Bass, Washington, DC, USA, 1984.

[14] G. W. Lundeen, C. Tenopir, and P. Wermager, "Information needs of rural health care practitioners in Hawaii," Bulletin of the Medical Library Association, vol. 82, no. 2, pp. 197-205, 1994.

[15] T. R. Long, B. A. Elliott, M. E. Warner, M. J. Brown, and S. H. Rose, "Resident and program director gender distribution by specialty," Journal of Women's Health, vol. 20, no. 12, pp. 18671870, 2011.

[16] A. Barilan, T. Haimov, K. Doplet, S. Matnick, S. Vinker, and E. Kitai, "Workload, burnout and need to recover among female residents in internal medicine and family medicine," Harefuah, vol. 150 , no. 8, pp. 625-690, 2011.

[17] O. C. Castel, V. Ezra, M. Alperin et al., "Can outcomebased continuing medical education improve performance of immigrant physicians?" Journal of Continuing Education in the Health Professions, vol. 31, no. 1, pp. 34-42, 2011.

[18] L. Forsetlund, A. Bjørndal, A. Rashidian et al., "Continuing education meetings and workshops: effects on professional practice and health care outcomes," Cochrane Database of Systematic Reviews, vol. 15, no. 2, Article ID CD003030, 2009.

[19] B. S. Bloom, "Effects of continuing medical education on improving physician clinical care and patient health: a review of systematic reviews," International Journal of Technology Assessment in Health Care, vol. 21, no. 3, pp. 380-385, 2005.

[20] I. Kerridge, "Pharmaceutical industry support for continuing medical education: is it time to disengage?" Journal of Paediatrics and Child Health, vol. 47, no. 10, pp. 690-692, 2011.

[21] A. Wazana, "Physicians and the pharmaceutical industry: is a gift ever just a gift?" The Journal of the American Medical Association, vol. 283, no. 3, pp. 373-380, 2000.
[22] P. R. Mansfield, "What do medical students think about pharmaceutical promotion?" Australian Medical Student Journal, vol. 1, pp. 54-57, 2010.

[23] D. Davis, G. Bordage, L. K. Moores et al., "The science of continuing medical education: terms, tools, and gaps," Chest, vol. 135, no. 3, supplement, pp. 8S-16S, 2009. 

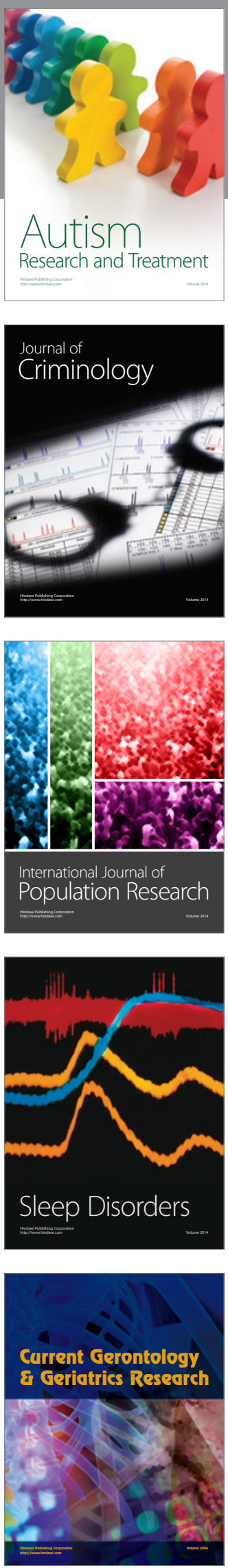
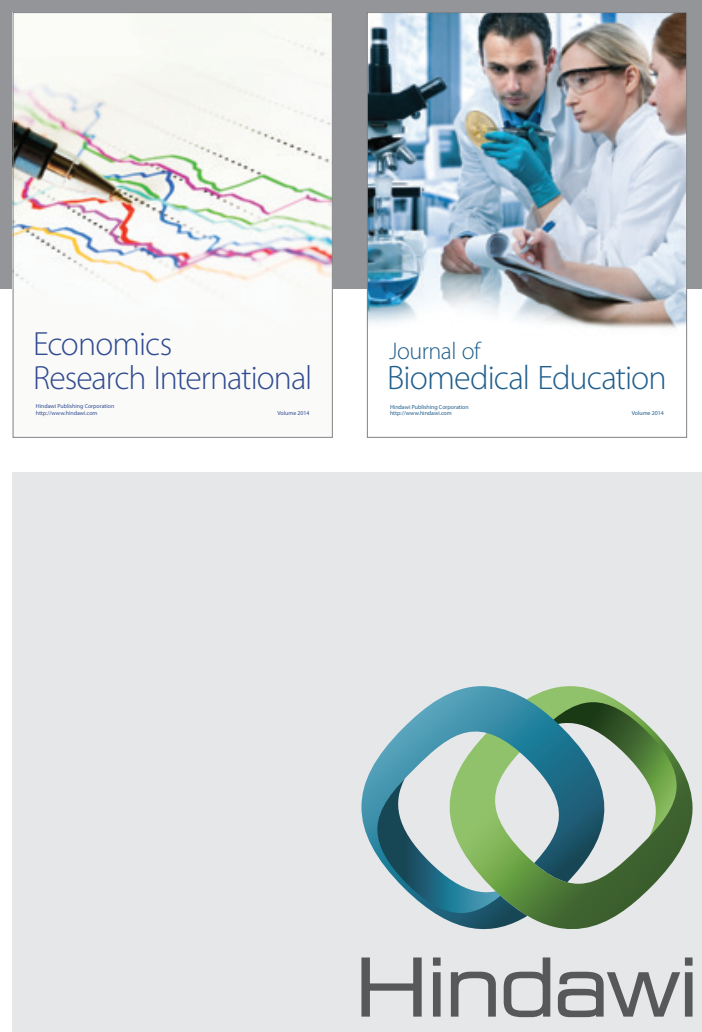

Submit your manuscripts at

http://www.hindawi.com
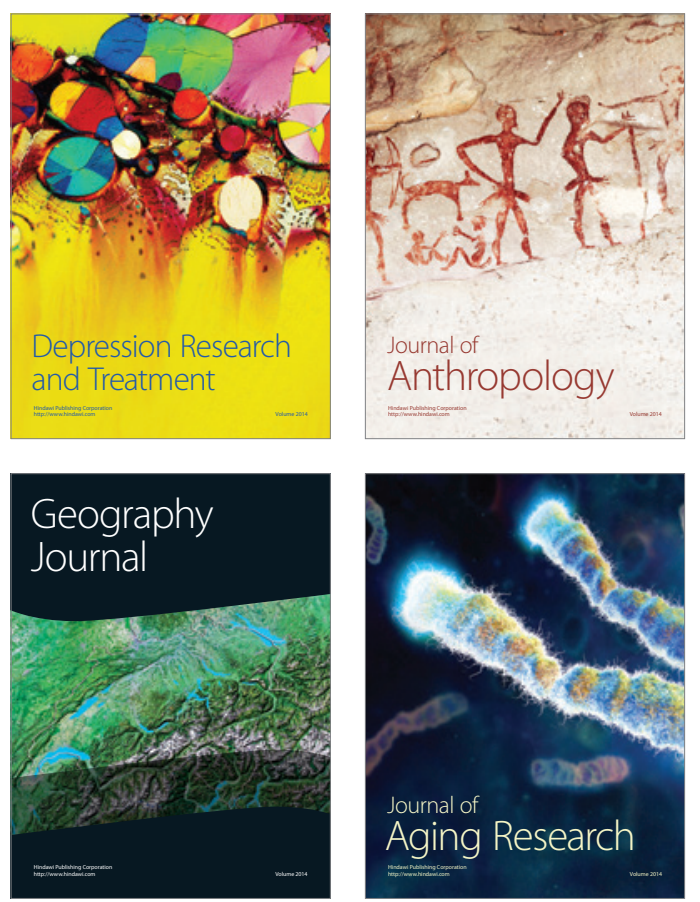
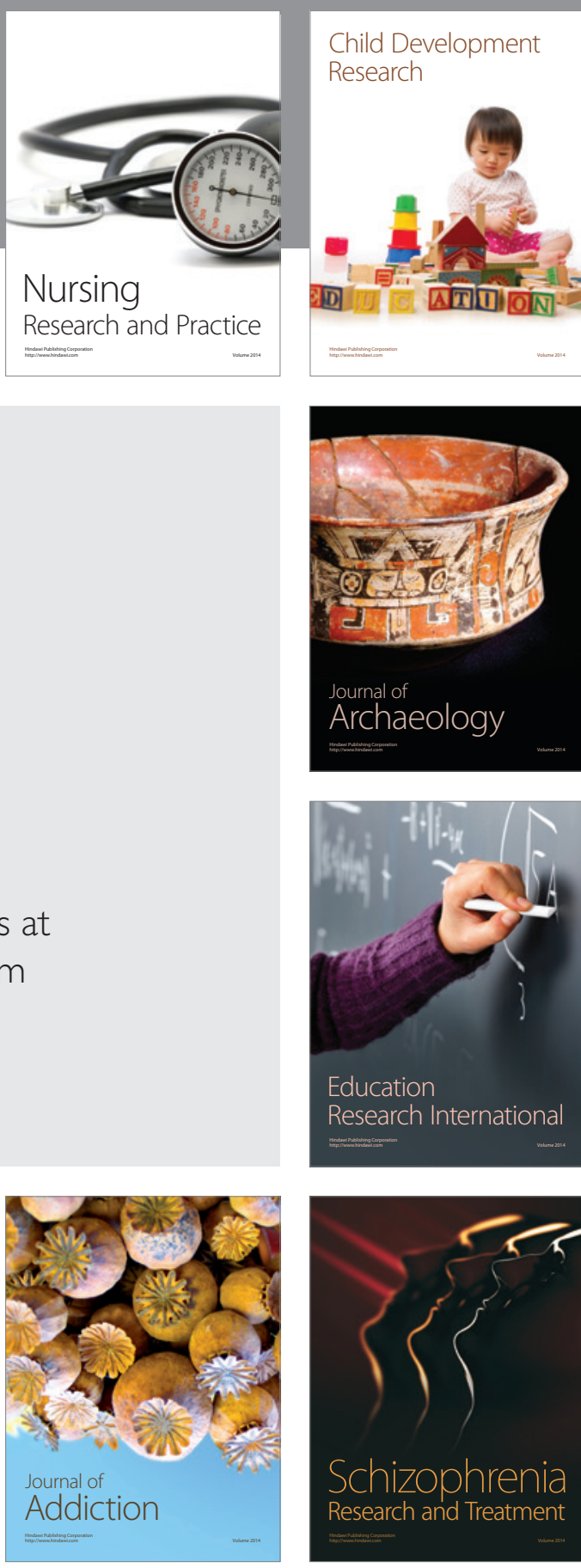

(D)
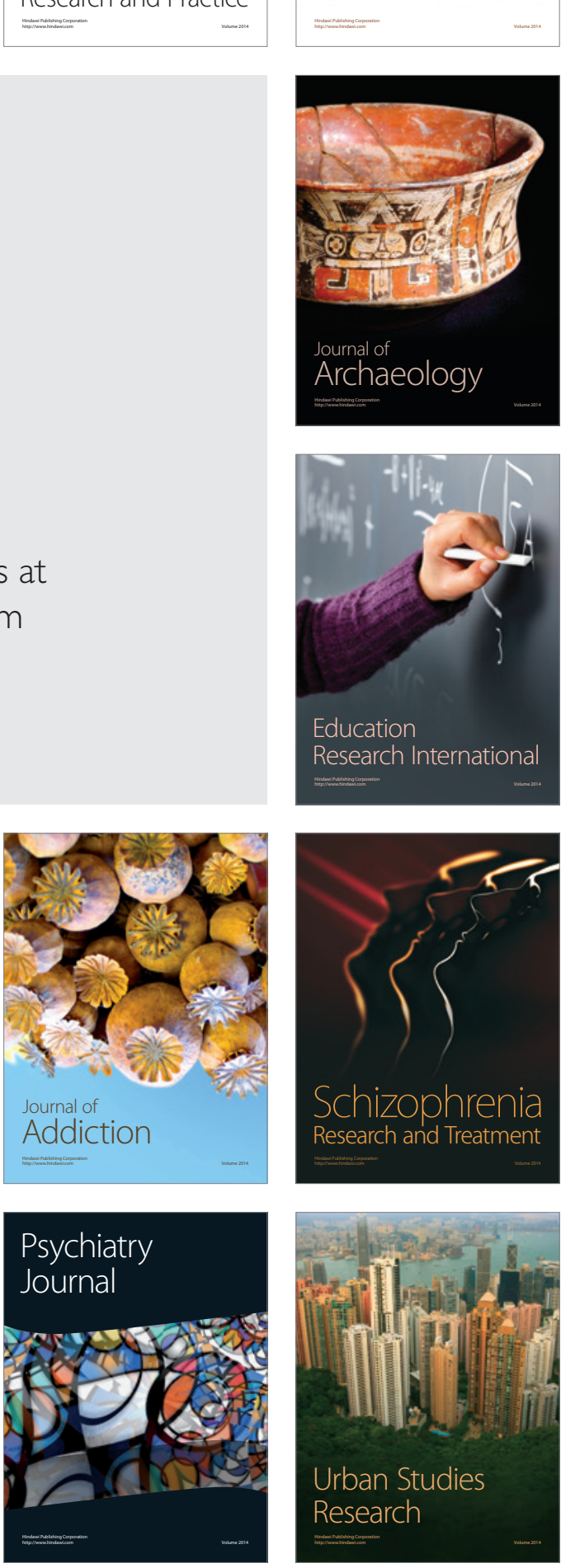